\title{
Self-esteem of patients with coronary artery disease
}

\author{
Autoestima de pacientes com doença arterial coronariana
}

Daniele Alcalá Pompeo ${ }^{1}$, Letícia Palota Eid ${ }^{2}$, Isabela Gonzales Carvalho ${ }^{1}$, Eduarda dos Santos Bertolli ${ }^{3}$ Natalia Serafim de Oliveira ${ }^{4}$

Objective: to evaluate the self-esteem of individuals with coronary artery disease. Methods: this is a crosssectional study, carried out with 77 participants. The instruments used were Hospital Anxiety and Depression Scale and Rosenberg Self-esteem Scale. Results: most of the participants had moderate self-esteem, 48 (62.3\%), followed by a low self-esteem, $29(37.7 \%)$, being influenced by the variables gender $(\mathrm{p}=0.040)$, education level $(\mathrm{p}=0.009)$, anxious symptoms $(\mathrm{p}=0.010)$ and depressive $(\mathrm{p}=0.030)$. Conclusion: patients with coronary artery disease presented medium and low self-esteem scores. Higher levels of self-esteem were associated with females, higher education level and the presence of anxiety and depression symptoms.

Descriptors: Coronary Disease; Self Concept; Adjustment Disorders.

Objetivo: avaliar a autoestima de indivíduos com doença arterial coronariana. Métodos: estudo transversal, realizado com 77 participantes. Foram utilizados os instrumentos: Escala Hospitalar de Ansiedade e Depressão e Escala de Autoestima de Rosenberg. Resultados: a maioria dos participantes obteve autoestima moderada $48(62,3 \%)$, seguida de baixa $29(37,7 \%)$, sendo influenciada pelas variáveis: sexo $(\mathrm{p}=0,040)$, escolaridade $(p=0,009)$, sintomas ansiosos $(p=0,010)$ e depressivos $(p=0,030)$. Conclusão: pacientes com doença arterial coronariana apresentaram médios e baixos escores de autoestima. Níveis mais elevados de autoestima foram associados ao sexo feminino, maior escolaridade e à presença de sintomas de ansiedade e depressão.

Descritores: Doença das Coronárias; Autoimagem; Transtornos de Adaptação.

\footnotetext{
${ }^{1}$ Faculdade de Medicina de São José do Rio Preto. São José do Rio Preto, SP, Brazil.

${ }^{2}$ Universidade Federal de Goiás. Jataí, GO, Brazil.

${ }^{3}$ Hospital de Base. São José do Rio Preto, SP, Brazil.

${ }^{4}$ Universidade Paulista. São José do Rio Preto, SP, Brazil.

Corresponding author: Daniele Alcalá Pompeo

Avenida Brigadeiro Faria Lima, 5416, Vila São Pedro. CEP: 15090-000. São José do Rio Preto, SP, Brazil. E-mail: daniele.pompeo@famerp.br
} 


\section{Introduction}

Statistical data from the American Heart Association showed that, although there was a decline in mortality rates attributed to cardiovascular diseases between 2003 and 2013, these diseases accounted for one in three deaths, representing $30.8 \%$ of all deaths, in the United States. Also, coronary artery disease alone caused one in seven deaths in that same expansion of basic services and preventive measures, cardiovascular diseases still period ${ }^{(1)}$.

Thus, it is necessary to adopt preventive measures against modifiable risk factors such as hypertension, diabetes mellitus, smoking, dyslipidemia, obesity, sedentary lifestyle and psychosocial factors, as well as the promotion of healthy behaviors and lifestyle modification to achieve the goal of reducing deaths attributable to cardiovascular diseases and stroke by $20.0 \%$ by $2020^{(1)}$.

Although the Brazilian government has increased investments in resources to expand basic services and preventive measures, cardiovascular diseases still account for $80.0 \%$ of medical care, being the third cause of hospitalization. The impact of morbidity related to these diseases mainly affects young adults, who are frequently exposed to negative changes in the contemporary lifestyle ${ }^{(2)}$.

In the last decades, studies have shown that psychosocial factors play an important role in the morbidity and mortality of coronary diseases. However, in spite of being frequent, these psychiatric conditions are poorly recognized and may persist for a prolonged period, with a substantial impact on the quality of life of these patients and interfere with the capacity for self-care and adaptation to a new lifestyle ${ }^{(3-4)}$.

Anxiety and depression are the most present psychiatric disorders in this population. The national and international literature shows several studies demonstrating the high prevalence of these conditions in patients with coronary artery disease ${ }^{(3,5-6)}$. Also, recent research shows evidence that anxiety and depression constitute independent causes for the deve- lopment of cardiovascular diseases, emphasizing that they are as important as the other risk factors already established in the literature ${ }^{(3)}$, such as smoking, obesity and unhealthy lifestyle habits.

Other aspects related to mental health have also been mentioned in the literature as factors that influence the appearance of these diseases, such as resilience $^{(5)}$, stress and personality type ${ }^{(7)}$ and negative emotions ${ }^{(8)}$.

Self-esteem is a key component of mental health. This subjective construct is defined as an attitude of approval or self-reproach and encompasses self-judgment in the competence and value. Low self-esteem is characterized by feelings of incompetence, the inadequacy of life and inability to overcome challenges. However, high self-esteem involves a sense of self-confidence and competence ${ }^{(9)}$.

Recent research suggests that high self-esteem may be associated with an improvement in the functioning of the parasympathetic nervous system, which may confer cardiovascular benefits and protect the effects of stress and anxiety(10-11).

Low self-esteem has been associated in some studies with anxiety and depression ${ }^{(11-12)}$. However, the literature is scarce regarding the association of this variable with cardiovascular diseases. In this way, knowing this scenario can elucidate strategies to identify and strengthen the self-esteem of people affected by coronary diseases.

Therefore, the objective of this research was to evaluate the self-esteem of individuals with coronary artery disease.

\section{Methods}

This is a cross-sectional study, developed in a Clinical and Surgical Hospitalization Unit for the cardiovascular specialty of a School Hospital in the interior of the State of São Paulo. The hospital is a large public institution, with 102 municipalities in the Northwest region of the State of São Paulo, with a total of 629 beds and 53,000 monthly visits. 
The population consisted of patients with coronary artery disease hospitalized, regardless of gender, and aged 18 years or over. The exclusion criteria were: unable to communicate verbally and not have cognitive conditions that allow participation in the study, verified through the ability to inform their age or date of birth, residential address, the day of the week and month. Participants who met the inclusion criteria were selected by means of consecutive and non-probabilistic sampling $(\mathrm{n}=77)$.

Three instruments were used to collect the data: socio-demographic characterization (gender, age, partner's presence, education level, income and work activity), Hospital Anxiety and Depression Scale Hospital Anxiety and Depression Scale ${ }^{(13)}$ and Rosenberg Self-esteem Scale ${ }^{(9)}$.

The Hospital Anxiety and Depression Scale is easy to handle and fast to perform. It has 14 items, seven for anxiety assessment and seven for depression assessment. Each item includes four answers from zero to three, totaling a maximum score of 21 points for each subscale. Anxiety is considered when the score is greater or equal to nine and without anxiety when it is between zero and eight points. Likewise, depression is considered when the score is greater or equal to nine and without depression when it is between zero and eight points ${ }^{(13)}$.

The Rosenberg Self-Esteem Scale has been translated and adapted to use it in Brazil and it consists of 10 items with four possible answers: 1 - strongly agree, 2 - agree, 3 - disagree, 4 - strongly disagree. The measure of self-esteem is obtained by summing the values of the responses to the scale items, after re-coding the five items with the reverse score. The sum of the answers can vary from 10 to 40 , and the self-esteem classified as high or satisfactory (greater than 30 points), average (from 20 to 30 points) and low or unsatisfactory (less than 20 points) ${ }^{(14)}$.

Data collection was in the second half of 2015, through an interview, verbally applied by the interviewer.

Data were processed and analyzed using Statis- tical Package for Social Science, version 19 for Windows IBM Company Copyright 2010. For the descriptive analysis, position measures (mean and median) and variability (standard deviation) were used. Qualitative data were associated with the use of the chi-square test. Patients' ages were compared with anxious and depressive symptomatology using the t-test for independent samples (when two sample groups were compared). The level of significance was set at 0.05.

The study complied with the formal requirements contained in the national and international regulatory standards for research involving human beings.

\section{Results}

Of the 77 participants, 50 (64.9\%) were males, ranging from 26 to 83 years old $(57.4 \pm 12.8)$. Most of them (44.1\%) reported having a partner and, in their professional activities, 43 (55.8\%) did not exercise them, due to reasons of their leave, to be retired or not to work.

Most of the interviewees, 30 (39.0\%), said they had the disease for more than five years and 22 (28.6\%) for a period of one to five years. When questioned about the presence of comorbidities, 54 (70.1\%) denied any associated disease. Also, 64 (83.1\%) reported not having a smoking habit, $56(72.7 \%)$ denied alcoholism and 43 (55.8\%) reported having a stressed personality. Most of the patients, 53 (68.8\%), mentioned that the disease interferes with their activities of daily living.

Regarding the self-esteem scores, 48 (62.3\%) participants had moderate self-esteem and 29 (37.7\%) had low self-esteem. No patient was evaluated with high self-esteem. Self-esteem was influenced by variables: gender $(\mathrm{p}=0.040)$, education level $(\mathrm{p}=0.009)$, anxiety $(\mathrm{p}=0.010)$ and depressive symptoms $(\mathrm{p}=0.030)$. The highest self-esteem scores were present in women, with higher educational level and with anxious and depressive symptomatology, according to Table 1. 
Table 1 - Self-esteem of the participants, according to sociodemographic and clinical variables

\begin{tabular}{lccc}
\hline \multirow{2}{*}{ Variables } & \multicolumn{2}{c}{ Self-esteem } & \multirow{2}{*}{$\mathbf{p}^{*}$} \\
\cline { 2 - 3 } & $\begin{array}{c}\text { Low } \\
\mathbf{n}(\%)\end{array}$ & $\begin{array}{c}\text { Mean } \\
\mathbf{n}(\%)\end{array}$ & \\
\hline Gender & & & \\
$\quad$ Female & $6(22.2)$ & $21(77.8)$ & 0.040 \\
$\quad$ Male & $23(46.0)$ & $27(54.0)$ & \\
Education level & & & \\
$\quad$ Without study & $28(44.4)$ & $35(55.6)$ & 0.009 \\
$\quad$ Literate & $1(7.1)$ & $13(92.9)$ & \\
Anxiety & & & \\
$\quad$ Yes & $3(14.3)$ & $18(85.7)$ & 0.010 \\
$\quad$ No & $26(46.4)$ & $30(53.6)$ & \\
Depression & & & \\
$\quad$ Yes & $2(13.3)$ & $13(86.7)$ & 0.030 \\
$\quad$ No & $27(43.5)$ & $35(56.5)$ & \\
*Chi-Square test & & &
\end{tabular}

There were no associations of self-esteem with the presence of a partner $(\mathrm{p}=0.497)$, comorbidities ( $p=0.393)$, interference with daily life activities $(\mathrm{p}=0.319)$ and personality $(\mathrm{p}=0.130)$.

The anxiety symptoms were present in 21 (27.3\%) participants and the depression symptoms were present in 15 (19.5\%) of them. These symptoms were associated with the following variables: gender, comorbidities, interference in daily life activities and personality, according to Table 2 .
The women presented more anxious and depressive symptoms when compared to the men $(\mathrm{p}=0.013, \mathrm{p}=0.004)$. Participants who had comorbidities associated with heart disease had more depressive symptoms than those without comorbidities $(\mathrm{p}=0.027)$. Patients who mentioned that the disease interfered with their daily life activities were associated with the presence of depressive symptoms $(\mathrm{p}=0.022)$. In the same sense, individuals who self-rated with a stressed personality had more anxious $(\mathrm{p}=0.007)$ and depressive symptoms $(\mathrm{p}=0.001)$ when compared to the others.

There were no significant associations between anxiety and depressive symptoms with the following variables: education level $(\mathrm{p}=0.148, \mathrm{p}=0.342)$, presence of a partner $(\mathrm{p}=0.301, \mathrm{p}=0.361)(\mathrm{p}=0.875$, $\mathrm{p}=0.775)$, time of illness ( $\mathrm{p}=0.511, \mathrm{p}=0.815)$, smoking $(\mathrm{p}=0.709, \mathrm{p}=0.683)$ and alcohol consumption. Presence of comorbidities and disease interference in activities of daily living were not statistically associated with anxiety symptoms.

The t-test results for independent samples showed that age did not influence the symptoms of anxiety $(p=0.067)$ and depression (0.772) in the evaluated patients.

Table 2 - Symptoms of anxiety and depression of participants, according to sociodemographic and clinical variables

\begin{tabular}{|c|c|c|c|c|c|c|}
\hline \multirow[b]{2}{*}{ Variables } & \multicolumn{2}{|c|}{ Anxiety } & \multirow[b]{2}{*}{$\mathbf{p}^{*}$} & \multicolumn{2}{|c|}{ Depression } & \multirow[b]{2}{*}{$\mathbf{p}^{*}$} \\
\hline & $\begin{array}{c}\text { Yes } \\
\text { n(\%) }\end{array}$ & $\begin{array}{c}\text { No } \\
\mathbf{n}(\%)\end{array}$ & & $\begin{array}{c}\text { Yes } \\
\text { n(\%) }\end{array}$ & $\begin{array}{c}\text { No } \\
\text { n(\%) }\end{array}$ & \\
\hline \multicolumn{7}{|l|}{ Gender } \\
\hline Female & $12(44.4)$ & $15(55.6)$ & \multirow{2}{*}{0.013} & $10(37.0)$ & $17(63.0)$ & \multirow{2}{*}{0.004} \\
\hline Male & $9(18.0)$ & $41(82.0)$ & & $5(10.0)$ & $45(90.0)$ & \\
\hline \multicolumn{7}{|c|}{ Comorbidities } \\
\hline Yes & $8(34.8)$ & $15(65.2)$ & \multirow{2}{*}{0.334} & $8(34.8)$ & $15(65.2)$ & \multirow{2}{*}{0.027} \\
\hline No & $13(24.1)$ & $41(75.9)$ & & $7(13.0)$ & $47(87.0)$ & \\
\hline \multicolumn{7}{|c|}{ Interference of disease in activities of daily living } \\
\hline Yes & $17(32.1)$ & $36(67.9)$ & \multirow{2}{*}{0.160} & $14(26.4)$ & $39(73.6)$ & \multirow{2}{*}{0.022} \\
\hline No & $4(16.7)$ & $20(83.3)$ & & $1(4.2)$ & $23(95.8)$ & \\
\hline \multicolumn{7}{|c|}{ Stressed personality report } \\
\hline Yes & $17(39.5)$ & $26(60.5)$ & \multirow{2}{*}{0.007} & $14(32.6)$ & $29(67.4)$ & \multirow{2}{*}{0.001} \\
\hline No & $4(11.8)$ & $30(88.2)$ & & $1(2.9)$ & $33(97.1)$ & \\
\hline
\end{tabular}




\section{Discussion}

This study was limited by time and cross-sectional design, and it is not possible to follow up the patient in the long term to assess in which phase of heart disease the patient initiated lower levels of self-esteem and elevated anxiety and depressive symptoms. However, these results elucidate the need for an integral evaluation of the coronary disease patient, as well as showing possibilities of action to prevent or minimize heart disease.

The results of this study showed moderate and low self-esteem in its participants. The prevalence of low self-esteem was found in the literature in patients with chronic diseases such as idiopathic thrombocytopenic purpura ${ }^{(15)}$ and obesity ${ }^{(16)}$. Therefore, it is observed that the levels of self-esteem can be negatively affected by the chronic disease, and this fact is related to the onerous consequences of the disease, decreased coping capacity and impaired resilience ${ }^{(15)}$.

Some studies have shown that the duration of the disease has a direct effect on patients' self-esteem since long-term treatments negatively affect this variable $^{(15,17)}$. Low self-esteem scores, especially in chronic diseases, have a negative impact on patients' interpersonal relationships, thoughts, feelings and daily life activities ${ }^{(17)}$, which compromises their ability to manage disease and make them more vulnerable to acute events.

Patients suffering from coronary diseases often experience a feeling of loss of self-control, since the disease requires a more regulated life, with modifications in diet, physical exercises, use of medications, among other impositions. This fact is a risk factor for low self-esteem, and consequently for a reduction in quality of life, an increase in the prevalence of depression and other physical diseases ${ }^{(4)}$.

A recent study showed that low levels of self-esteem were associated with a higher frequency and duration of hospitalization, reduced quality of life, functional impairment, prolonged use of medications with adverse side effects, changes in appearance and changes in the psychological state of patients ${ }^{(15)}$.

Considering that the genesis of acute coronary syndromes involves ischemic pathophysiological mechanisms and that some chronic non-controlled diseases are the main promoters of the atherosclerotic process, especially systemic arterial hypertension and diabetes mellitus ${ }^{(1)}$, the prevalence of low and moderate self-esteem in the population of this study may be associated, in part, with the presence of underlying cardiovascular and metabolic diseases.

Our study found that high levels of self-esteem were more present in female subjects, with higher education level and with symptoms of anxiety and depression.

The literature shows opposite results, demonstrating that the self-esteem deficits were associated with the presence of anxiety ${ }^{(10-11)}$. An American study conducted with 858 participants confirmed the cause and effect relationship of anxiety disorders in the development of heart disease. Elevated self-esteem has been associated with cardiovascular protection since it leads to a reduction of anxiety, blood pressure levels and cardiovascular reactivity ${ }^{(10)}$.

A longitudinal research conducted with 1641 patients in the Netherlands suggests that reduced self-esteem scores are related to high levels of anxious and depressive symptoms ${ }^{(11)}$. Another important research corroborates these data, focusing on the fact that low self-esteem is predictive of depression and anxiety, and it is also strongly associated with females ${ }^{(12)}$.

It is believed that in this study, although the highest values of self-esteem were present in female patients, and in those with anxious and depressive symptoms, it is noteworthy that all of them had moderate and low self-esteem. No participants were rated with high self-esteem.

Regarding the educational level, this research demonstrated a positive association between education level and self-esteem. A similar result was found in an Iranian study that showed a strong association 
between these variables ( $r=0.36, p<0.003$ ), suggesting that the higher the study years, the greater the self-esteem ${ }^{(15)}$.

The symptoms of anxiety and depression were present in $27.3 \%$ and $19.5 \%$ of the patients, respectively. Similar findings were found in other studies, which also demonstrated the important prevalence of anxiety and depression symptoms in the same population $^{(3,5)}$.

Our data corroborate the results of a large European study involving more than 7589 patients hospitalized for coronary events ${ }^{(3)}$. Their findings demonstrated a prevalence of $26.3 \%$ and $22.4 \%$ of anxiety and depression, respectively, being positively related to females, lower educational level and more sedentary lifestyle $\mathrm{e}^{(3)}$.

Although the literature is consistent with the high prevalence of psycho-affective symptoms in patients with coronary diseases, there is evidence of low rates of anxiolytic and antidepressant treatment in this population ${ }^{(3)}$, suggesting that the existence of these emotional manifestations in patients with coronary diseases is not evaluated consistently or valued and, therefore, little diagnosed and treated.

A large prospective cohort study documented that anxiety is associated with increased risk of cardiovascular disease and mortality in initially healthy participants ${ }^{(6)}$. There is also evidence that the presence of anxious and depressive symptoms negatively impacts the quality of life scores in these patients ${ }^{(4)}$.

The contribution of depression and anxiety disorders to the development and worsening of these diseases is still unclear. Several hypotheses have been developed to explain this association. One of the main factors mentioned is the influence of anxious symptoms on the elevation of blood pressure levels, including morning values ${ }^{(18)}$, which constitutes an independent risk factor for cardiovascular complications.

Also, negative behaviors related to stress control, such as increased alcohol and tobacco consumption and decreased physical exercise are associated in the scientific literature to higher rates of anxiety, depression and heart disease. Stress, anxiety and depression act as obstacles to lifestyle modification, hindering to achieve therapeutic goals, and conferring a greater cardiovascular risk on the individual ${ }^{(7-8)}$.

In this study, women presented more anxious and depressive symptoms when compared to men. The literature demonstrates significant differences in susceptibility to myocardial ischemia triggered by emotional stress according to gender and age, with young women presenting greater evidence of this clinical condition among patients with coronary disease. Impaired psychosocial conditions are related to increased morbidity and mortality among young women with ischemic heart disease ${ }^{(19)}$, but as mental stress, in a unique way, modulates the course of women is still unclear.

There is scientific evidence that women experience emotions, particularly those with a negative valence, such as fear, anger, and sadness, with greater intensity than men. Also, women often engage in emotion-focused coping strategies and report a greater negative impact than men on stress, which are predictive of anxious and depressive symptomatology ${ }^{(8)}$.

In this study, depression also showed a positive association with the presence of comorbidities, corroborating a study that evaluated anxiety, depression, resilience and self-esteem in patients with cardiovascular diseases $^{(5)}$. Also, manifestations of depression were also more present in patients who reported that coronary artery disease interfered with their daily activities. A similar result was found in a recent study ${ }^{(4)}$. It is believed that this is one of the factors that negatively interfere with the quality of life in these patients.

In the same sense, in this study, individuals who self-assessed with a stressed personality had more anxious and depressive symptoms when compared to the others. Recent research corroborates these results, demonstrating a positive association between stressed personality and higher levels of anxiety and depression. Also, this variable proved to be an independent predictor of major adverse cardiac events in patients with coronary artery disease ${ }^{(7)}$. 
It is observed that the scientific evidences of this study and the literature make clear about the multiplicity of elements involved in the genesis of cardiovascular diseases and how the psychological factors can contribute to the development, evolution or rehabilitation of cardiac pathologies, demonstrating the importance of understanding these aspects and their relation to these diseases, to the base of preventive approaches.

\section{Conclusion}

It was concluded that the levels of self-esteem of the patients with coronary artery disease evaluated in this investigation were average and low. Higher levels of self-esteem were associated with females, higher education levels and the presence of anxiety and depression symptoms. The anxious and depressive symptomatology was relevant in the studied sample, presenting an association with the females and a report of a stressed personality. Depression was associated with a higher frequency of comorbidities and interference in patients' daily life activities.

\section{Collaborations}

Pompeo DA contributed to the project design, data analysis and interpretation, article writing, critical review of the intellectual content and final approval of the version to be published. Eid LP contributed to the writing of the article, relevant critical review of the intellectual content and final approval of the version to be published. Carvalho IG, Bertolli ES and Oliveira NS contributed to the design, analysis, and interpretation of data.

\section{References}

1. Mozaffarian D, Benjamin EJ, Go AS, Arnett DK, Blaha MJ, Cushman M, et al. AHA Statistical Update: heart disease and stroke statistics-2016 update: a report from the American Heart Association. Circulation. 2016; 133(4):e38-360. doi:http://dx.doi. org/10.1161/CIR.0000000000000350
2. Villela LCM, Gomes FE, Meléndez JGV. Mortality trend due to cardiovascular, ischemic heart diseases, and cerebrovascular disease. Rev Enferm UFPE on line [Internet]. 2014 [cited 2017 Apr. 13]; 8(9):313441. doi: Available from: http://www.revista.ufpe. $\mathrm{br} /$ revistaenfermagem/index.php/revista/article/ viewArticle/4949

3. Pogosova N, Kotseva K, Bacquer D, Von Känel R, Smedt D, Bruthans J, et al. Psychosocial risk factors in relation to other cardiovascular risk factors in coronary heart disease: results from the EUROASPIRE IV survey. A registry from the European Society of Cardiology. Eur J Prev Cardiol. 2017; 24(13):1371-80. doi: http://dx.doi. org/10.1177/2047487317711334

4. Tusek-Bunc K, Petek D. Comorbidities and characteristics of coronary heart disease patients: their impact on health-related quality of life. Health Qual Life Outcomes [Internet]. 2016 [cited 2017 Apr. 13]; 14(1):159. Available from: https://www.ncbi. nlm.nih.gov/pubmed/27846850

5. Carvalho IG, Bertolli ED, Paiva L, Rossi LA, Dantas RA, Pompeo DA. Anxiety, depression, resilience and selfesteem in individuals with cardiovascular diseases. Rev Latino-Am Enfermagem. 2016; 24:e2836. doi: http://dx.doi.org/10.1590/1518-8345.1405.2836

6. Celano CM, Daunis DJ, Lokko HN, Campbell KA, Huffman JC. Anxiety disorders and cardiovascular disease. Curr Psychiatry Rep. 2016; 18(11):101. doi: http://dx.doi.org/10.1007/s11920-016-0739-5

7. Du J, Zhang D, Yin Y, Zhang X, Li J, Liu D, et al. The personality and psychological stress predict major adverse cardiovascular events in patients with coronary heart disease after percutaneous coronary intervention for five years. Medicine (Baltimore). 2016; 95(15):e3364. doi: http://dx.doi. org/10.1097/MD.0000000000003364

8. Victor TA, Drevets WC, Misaki M, Bodurka J, Savitz J. Sex differences in neural responses to subliminal sad and happy faces in healthy individuals: Implications for depression. J Neurosci Res. 2017; 95(1-2):70310. doi: http://dx.doi.org/10.1002/jnr.23870

9. Rosenberg M. Society and the adolescent self-image. Science. 1965; 148(3671):804. doi: http://dx.doi. org/10.1126/science.148.3671.804 
10. Edmondson D, Arndt J, Alcántara C, Chaplin W, Schwartz JE. Self-esteem and the acute effect of anxiety on ambulatory blood pressure. Psychosom Med. 2015; 77(7):833-41. doi: http://dx.doi. org/10.1097/PSY.0000000000000219

11. Van Tuijl LA, Jong PJ, Sportel B, Hullu E, Nauta MH. Implicit and explicit self-esteem and their reciprocal relationship with symptoms of depression and social anxiety: A longitudinal study in adolescents. J Behav Ther Exp Psychiatry. 2014; 45(1):113-21. doi: http://dx.doi.org/10.1016/j.jbtep.2013.09.007

12. Tripkovic I, Roje R, Krnic S, Nazor M, Karin Z, Capkun $\mathrm{V}$. Depression and self-esteem in early adolescence. Cent Eur J Public Health [Internet]. 2015 [cited 2017 Apr. 13]; 23(2):142-5. Available from: https://www. ncbi.nlm.nih.gov/pubmed/26851429

13. Zigmond AS, Snaith RP. The hospital anxiety and depression scale. Acta Psychiatr Scand [Internet]. 1983 [cited 2017 May. 13]; 67(6):361-70. Available from: https://www.ncbi.nlm.nih.gov/ pubmed/6880820

14. Dini DM, Ferreira LM, Quaresma MR. Translation into Portuguese, cultural adaptation and validation of the Rosenberg self-esteem scale. Rev Soc Bras Cir Plast [Internet]. 2004 [cited 2017 May. 13]; 19(1):41-52. Available from: http://www.rbcp.org.br/imagebank/ pdf/19-01-04pt.pdf
15. Hemati Z, Kiani D. The Relationship between selfesteem and quality of life of patients with idiopathic thrombocytopenic purpura at Isfahan's Sayed Alshohada Hospital, Iran, in 2013. Int J Hematol Oncol Stem Cell Res [Internet]. 2016 [cited 2017 Apr. 14]; 10(2):79-84. Available from: https://www.ncbi.nlm. nih.gov/pubmed/27252807

16. Hill AJ. Obesity in children and the 'myth of psychological maladjustment': self-esteem in the spotlight. Curr Obes Rep. 2017; 6(1):63-70. doi: http://dx.doi.org/10.1007/s13679-017-0246-y

17. Ghodusi M, Heidari M, Ali Sheikhi R, Shirvani M. The Relation Between Body Esteem With Self Esteem And Perceived Social Support In Multiple Sclerosis Patients - Assessment. Natl J Integr Res Med [Internet]. 2016 [cited 2017 Apr. 14]; 7(1):7-11. Available from: http://www.scopemed. org/?mno=221277

18. Ozpelit ME, Ozpelit E, Dogan NB, Pekel N, Ozyurtlu F, Yllmaz A, et al. Impact of anxiety level on circadian rhythm of blood pressure in hypertensive patients. Int J Clin Exp Med [Internet]. 2015 [cited 2017 Apr. 14]; 8(9):16252-8. Available from: https://www. ncbi.nlm.nih.gov/pmc/articles/PMC4659029/

19. Dreyer RP, Smolderen KG, Strait KM, Beltrame JF, Lichtman JH, Lorenze NP, et al. Gender differences in pre-event health status of young patients with acute myocardial infarction: a VIRGO study analysis. Eur Heart J Acute Cardiovasc Care. 2016; 5:43-54.doi: http://dx.doi.org/10.1177/2048872615568967 